\title{
Concepções de educação ambiental na mídia e em práticas escolares: contribuições de uma tipologia
}

\author{
Rosana Louro Ferreira da Silva ${ }^{1}$ \\ Nilva Nunes Campina ${ }^{2}$
}

Resumo: Partindo da constatação de que existe uma pluralidade de ações em educação ambiental, o objetivo central deste trabalho é apresentar e aplicar uma tipologia que possibilite a identificação das concepções de educação ambiental presentes em materiais e práticas escolares. Para a tipologia foram eleitas três categorias de concepção de educação ambiental: conservadora, pragmática e crítica. Para cada concepção foram agrupadas cinco dimensões de análise: relação ser humano-meio ambiente, ciência e tecnologia, valores éticos, política e atividades sugeridas. A tipologia foi utilizada em três pesquisas: análise de filmes didáticos, imagens de capas de revistas e práticas escolares. Ressalta-se que esta investigação foi realizada em uma visão propositiva, uma vez que se procurou estabelecer algumas diretrizes e sugestões para a análise da pluralidade das práticas de educação ambiental e trazer possibilidades de escolha consciente, com critérios mais claros, para os professores e profissionais da área.

Palavras-chave: Concepções. Tipologia. Pluralismo.

Abstract: Starting from the observation that there are a plurality of actions within environmental education, the main objective of this paper is to present a typology that allows the identification of environmental education concepts present in educational practices and materials. Three categories of environmental education conception were chosen for the typology: conservative, pragmatic and critical. For each conception, five analysis dimensions were grouped: human being-environment relationship, science and technology, ethical values, politics and suggested activities. The typology was used in three different moments: analysis of instructional films, analysis of magazine covers and analysis of school practices. It should be emphasized that this research was conducted in a purposeful view, because we tried to establish some guidelines and suggestions for analyzing the plurality of environmental education practices and providing teachers and professionals in the field with clearer criteria to make conscious choices.

Keywords: Conception. Typology. Pluralism.

1 Professora da UFABC rosana.ferreira@ufabc.edu.br

2 Professora da UNIP nicampina@usp.br 


\section{Introdução}

A partir do reconhecimento de que a pesquisa em educação ambiental tem como principal objetivo "produzir conhecimentos sobre processos educativos críticos com compromisso de transformação das relações sociais e ambientais na perspectiva da emancipação" e de que é "preciso buscar qualidades dos processos educativos para compreendê-los" (Tozoni-Reis, 2008), entendemos que uma das possibilidades de pesquisa na área é a criação de instrumentos que permitam aos diferentes atores da educação ambiental (educadores, monitores, gestores, entre outros) o reconhecimento das características das diferentes propostas educativas que lhes são apresentadas, bem como a identificação de elementos importantes para a construção de práticas com características mais críticas.

Alguns autores têm discutido a necessidade da expressão educaşão ambiental (EA), uma vez que toda educação, a priori, seria ambiental. No entanto, acreditamos que o termo identifica uma área historicamente constituída e que vem acumulando produções teóricas e práticas. Nesse sentido, concordamos com Carvalho (2002, p. 85) que:

O atributo "ambiental", longe de cumprir apenas uma função adjetivante, ao especificar uma educação em particular, constitui um traço identitário da EA, marcando sua origem num contexto histórico determinado: os movimentos sociais ambientais e seu horizonte de crítica contracultural. É neste último sentido que o "ambiental" ganha uma função substantiva, ao demarcar o pertencimento desta educação a uma tradição ambiental e seu universo de valores, práticas e atores sociais. (Grifos da autora).

Não obstante essa identidade de origem, não existe uma única concepção de educação ambiental. Krasilchik $(1986,1994)$ já apontava essa definição como objeto de intensa controvérsia, não só no nosso país como também no âmbito internacional. Essa autora destaca o fato de que se agrupam sob a denominação educação ambiental atividades muito variadas, tanto em conteúdo como em valores.

Carvalho $(1998$, p. 114) procura tecer algumas reflexões a respeito do que chama "acontecimento ambiental", definido como "a emergência de um campo contraditório e diversificado de discursos e valores que constituem um amplo ideário ambiental". Essa diversificação também chegou aos fazeres educacionais relacionados à questão. Para a autora (1998, p. 114), a construção de uma prática educativa nomeada como EA ganha sentido "como parte da estruturação do campo ambiental e dos contextos políticos e culturais que este articula". Assim:

A EA está profundamente marcada pelos limites e possibilidades, bem como pelas disputas internas e externas do campo. É neste contexto de disputas que vão se delinear as diferentes ênfases e compreensões acerca da problemática ambiental e, por conseguinte, 
dos conceitos, programas, análises pedagógicas e políticas voltadas para a intervenção em EA (CARVALHO, 2002).

Pelo exposto, consideramos que a pluralidade é uma característica própria da educação ambiental, mas devem ser desenvolvidas estratégias para o reconhecimento e análise dessa pluralidade por professores. Nosso trabalho pretende contribuir para isso.

Recentemente, investigações vêm sendo realizadas por profissionais da área com o objetivo de mapear a produção da pesquisa em educação ambiental. Carvalho e Schmidt (2008) identificaram, com base na análise de trabalhos apresentados nos principais eventos da área, uma tendência importante no que se refere a uma categoria temática denominada os sentidos da $E A$, que reúne pesquisas voltadas para a identificação das representações, percepções e sentidos conferidos ao meio ambiente e à EA por grupos específicos, bem como para a reflexão e avaliação de práticas. No nosso entendimento, o reconhecimento da pluralidade da área e da existência de algumas identidades é o que fundamenta esse processo de busca de sentidos e se associa também a outras temáticas, como formação de professores, EA na educação formal e não formal, avaliação de materiais didáticos e de outras produções, entre outras.

A tipologia aqui apresentada, inicialmente desenvolvida em uma tese de doutoramento que analisou programas de meio ambiente na TV educativa (SILVA, 2007), foi utilizada posteriormente em outras duas situações: na análise de capas de revistas sobre temas ambientais e como um dos instrumentos de análise de outra pesquisa de doutorado, que realizou atividades pedagógicas relacionadas a biomonitoramento e educação ambiental.

Considerando a pesquisa em educação um processo social dinâmico, articulamos essas investigações neste trabalho, que tem por objetivos: apresentar a tipologia de análise de concepções de educação ambiental; analisar os resultados de sua aplicação em três pesquisas que buscaram identificar os sentidos da EA em práticas diversas; identificar os limites e possibilidades da própria tipologia e contribuir para a reflexão de um caminho a ser traçado que busque englobar as características de uma educação ambiental crítica, trazendo possibilidades de escolhas conscientes para os professores e profissionais da área.

\section{Concepções/identidades/sentidos da educação ambiental}

A categorização das diversas correntes e práticas de educação ambiental tem sido proposta por vários autores. Apontamos a seguir as revisões feitas por alguns deles.

Sorrentino (1998) tece considerações sobre os diversos fazeres educacionais voltados à questão ambiental e classifica-os, de forma bastante objetiva, em quatro grandes correntes: "conservacionista", "educação ao ar livre", "gestão ambiental" e "economia ecológica". Nesta quarta corrente, acredita estarem presentes duas vertentes: "desenvolvimento sustentável", aglutinando empresários, governantes e uma parcela das Organizações Não Governamentais, 
e "sociedades sustentáveis", composta por aqueles que sempre estiveram na oposição ao atual modelo de desenvolvimento. Identifica nesta segunda vertente alguns aspectos do Relatório do Fórum de ONGs Brasileiras para a Conferência da Sociedade Civil sobre Meio Ambiente e Desenvolvimento (1992) e do Tratado de Educação Ambiental para Sociedades Sustentáveis e de Responsabilidade Global (SORRENTINO, 1998, p. 28).

No âmbito internacional, Sauvé (2002) apresenta diversas correntes de educação ambiental, como naturalista, conservacionista, solução de problemas, sistêmica, holística, humanista, crítica, biorregional, feminista, entre outras. Em um artigo mais recente (SAUVÉ, 2005), essa autora aponta a existência de 15 correntes de educação ambiental:

- correntes que têm longa tradição: naturalista, conservacionista, resolutiva, sistêmica, científica, humanista, moral/ética;

- correntes mais recentes: holística, biorregionalista, práxica, crítica, feminista, etnográfica, da ecoeducação, da sustentabilidade.

Para identificar concepções de EA de atividades desenvolvidas em uma unidade de conservação, Mello (2000) as caracteriza em três grupos: grupo conservador, grupo da ecologia social e grupo da ecologia política.

Percebemos que essas categorizações geralmente partem de uma concepção mais ligada aos aspectos naturais até chegarem a uma concepção relacionada a uma visão mais integrada do meio ambiente, incluindo questões culturais, sociais, históricas, políticas, entre outras. Também é possível observar que a noção de sustentabilidade, pautada de um lado pelo desenvolvimento sustentável e de outro pelas sociedades sustentáveis, também caracteriza as diferentes concepções de EA.

De uma forma bastante genérica, Layrargues (2004, p. 7) assinala que a educação ambiental é o "nome que historicamente se convencionou dar às práticas educativas relacionadas à questão ambiental". O trabalho coordenado pelo autor, sob a responsabilidade do Ministério do Meio Ambiente, apresenta algumas "identidades" da EA: crítica, emancipatória, transformadora, ecopedagogia, educação no processo de gestão ambiental e alfabetização ecológica.

Diferentes abordagens de concepções e práticas de EA foram sintetizadas por Tozoni-Reis (2007) em cinco grandes grupos: educação ambiental como promotora de mudanças de comportamentos (disciplinatória e moralista); educação ambiental para a sensibilização ambiental (ingênua e imobilista); educação ambiental centrada na ação para a diminuição dos efeitos predatórios dos sujeitos (ativista e imediatista); educação ambiental centrada na transmissão de conhecimentos técnico-científicos (racionalista e instrumental) e educação ambiental como "processo político de apropriação crítica e reflexiva de conhecimentos, atitudes, valores e comportamentos que tem por objetivo a construção de uma sociedade sustentável do ponto de vista ambiental e social, sendo transformadora e emancipatória" (TOZONI-REIS, 2007, p. 179).

Pelo exposto, percebemos que no campo teórico da EA não existe um consenso sobre as concepções/correntes/identidades/grupos que permeiam suas práticas. 


\section{A construção da tipologia de análise - as concepções}

Embora tenhamos considerado a existência dessas categorizações, optamos por estabelecer uma tipologia própria de análise, incorporando as contribuições desses diversos autores e instituindo categorias detalhadas em dimensões a fim de possibilitar seu entendimento e uso em diferentes pesquisas, inclusive por professores e/ou profissionais da área ambiental que não estejam familiarizados com essa diversidade de concepções.

A tipologia foi construída em Silva (2007) para análise de programas de televisão educativa de meio ambiente e, posteriormente, foi utilizada em mais dois trabalhos de pesquisa: análise de imagens da mídia impressa e análise de práticas escolares.

No que se refere às concepções de educação ambiental, as categorias propostas em nossa tipologia foram: Educação Ambiental Conservadora, Educação Ambiental Pragmática e Educação Ambiental Crítica.

A categoria Educação Ambiental Conservadora está presente em quase todas as tipologias apresentadas. Suas concepções remontam à origem das práticas ambientalistas no contexto internacional, que, de acordo com Pelicioni (2005), partem de um ideário romântico, inspirador do movimento preservacionista do final do século XIX, no qual os vínculos afetivos proporcionados pela experiência de integração da natureza trariam bem-estar e equilíbrio emocional, bem como a valorização e proteção do ambiente natural. Essa perspectiva ainda está presente em muitos cursos e materiais de EA. Sua característica principal é a ênfase na proteção ao mundo natural. Também aparecem características do idilismo (KRASILCHIK, 1994), ou seja, da volta às condições primitivas de vida. São apresentados os problemas ambientais mais aparentes, desprezando-se as causas mais profundas. Ocorre uma relação dicotômica entre o ser humano e o ambiente, sendo o primeiro apresentado como destruidor. Praticamente não são abordadas questões sociais e políticas. As palavras-chave seriam: natureza, conservação, proteção e destruição.

A categoria Educação Ambiental Pragmática apresenta o foco na ação, na busca de soluções para os problemas ambientais e na proposição de normas a serem seguidas. Essa categoria de educação ambiental pode ter suas raízes no ambientalismo pragmático (CRESPO, 1998) e em concepções tecnicistas de educação. Busca mecanismos que compatibilizem desenvolvimento econômico com manejo sustentável de recursos naturais (desenvolvimento sustentável). A ênfase é na mudança de comportamento individual por meio da quantidade de informações e de normas ditadas por leis e por projetos governamentais, que são apresentados como soluções prontas. Embora haja o discurso da cidadania e sejam apresentadas questões sociais como parte do debate ambiental, os conflitos oriundos dessa relação ainda não aparecem ou aparecem na forma de um falso consenso. Loureiro (2004) aponta a existência de um grande bloco hegemônico de tendências que propõem um fazer pedagógico comportamentalista e tecnocrático, no qual entendemos estar incluída essa vertente pragmática. Esse mesmo autor afirma que o pragmatismo no 
ambientalismo caracteriza-se pelo pressuposto teórico e ideológico de que a gravidade da situação exige atitudes práticas, efetivas e exitosas em curto tempo. As palavras-chave são: mudança de comportamento, técnica, solução, desenvolvimento sustentável.

A Educação Ambiental Crítica, por sua vez, encontra suporte na perspectiva da educação crítica e no ambientalismo ideológico, descrito por Crespo (1998). É apresentada a complexidade da relação ser humano-natureza. Privilegia a dimensão política da questão ambiental e questiona o modelo econômico vigente. Apresenta a necessidade do fortalecimento da sociedade civil na busca coletiva de transformações sociais. No âmbito da história do ambientalismo, ao levar a problemática ambiental para a esfera pública, o ecologismo conferiu ao ideário ambiental a dimensão política (Carvalho, 2004). No contexto educacional, essa perspectiva baseia-se no pensamento crítico de Paulo Freire, entre outros autores, e propõe a constituição de uma ação educativa orientada para a transformação das estruturas econômicas, políticas e sociais vigentes. Nesse contexto, Reigota (1995) já destacava que a EA visa não só a utilização racional dos recursos naturais mas basicamente a participação dos cidadãos nas discussões e decisões sobre a questão ambiental.

$\mathrm{Na}$ proposta de uma EA crítica, a preocupação com as dimensões éticas e políticas é essencial. A mudança de comportamentos individuais é substituída pela construção de uma cultura cidadã e pela formação de atitudes ecológicas, o que supõe a formação de um sentido de responsabilidade ética e social (CARVALHO, 2004). As palavras-chave são: subjetividade, interdisciplinaridade, atitudes, cidadania ativa, sociedades sustentáveis.

Nesse sentido, conforme propõe Loureiro (2006, p. 70), para a tradição crítica não cabe:

[...] discutir conservação sem considerar os processos sociais que levaram ao atual quadro de esgotamento e extinção; falar em mudanças de comportamentos sem pensar como cada indivíduo vive, seu contexto e suas possibilidades concretas de fazer escolhas; defender uma forma de pensar a natureza, ignorando como cada civilização, cada sociedade e cada comunidade interagiam nela e definiam representações sobre ela; como produziam, geravam cultura e estilos de vida e como isso se dá hoje.

É importante ressaltar que não desconsideramos a importância das atividades de conservação ambiental, pois elas são absolutamente necessárias em alguns locais e situações. No entanto, para o ambiente escolar, as abordagens nessas perspectivas apresentam a questão ambiental de forma reducionista, o que pouco contribui para a construção de sociedades mais justas e que saibam exercer um papel ativo na busca de melhores condições socioambientais.

Nossa escolha sobre a concepção da EA Crítica para as atividades referentes à temática ambiental no contexto escolar e para a produção de material didático justifica-se, principalmente, pelo papel fundamental que essa concepção atribui à 
dimensão política e à práxis educativa. Nessa perspectiva, o conhecimento ambiental no universo escolar deve ir além de uma visão tradicional e comportamental, deve ir em direção a uma postura reflexiva e participativa que busque elementos para a consolidação de uma sociedade sustentável, partindo de pressupostos não apenas técnicos mas também políticos, éticos e ideológicos.

\section{As dimensões de análise}

A partir da busca de referenciais e elementos de cada uma das concepções descritas anteriormente, elencamos cinco dimensões de análise em cada uma das categorias, constituindo nossa proposta de tipologia. Sua construção foi embasada pelo referencial teórico a respeito das diferentes concepções de educação ambiental, pelas dimensões propostas por Carvalho $(2001,2006)$ e pelos elementos da análise de conteúdo (Bardin, 1977).

A análise de conteúdo é definida por Bardin (1977, p. 42) como "um conjunto de técnicas de análise das comunicações visando obter procedimentos sistemáticos e objetivos de descrição de conteúdo das mensagens". Busca inferir conhecimentos relativos às condições de produção/recepção de mensagens mediante a manipulação do seu conteúdo e da expressão desse conteúdo. Entre os instrumentos propostos nessa metodologia, foi utilizada a análise categorial, buscando-se identificar no conteúdo dos materiais concepções de educação ambiental predominantes.

Carvalho (2001) considera três dimensões fundamentais para a formação do educador na temática ambiental: 1) a dimensão relacionada à natureza dos conhecimentos presentes nos diferentes programas de formação; 2) a dimensão relacionada aos valores éticos e estéticos que têm sido veiculados pelos mesmos e 3) o tratamento dado às possibilidades de participação política do indivíduo, tendo como meta a formação de cidadãos e a construção de uma sociedade democrática. Em texto mais recente (2006) o autor refina tais dimensões, inserindo a dimensão política como central e as dimensões de conhecimento e valores como dimensões de complementaridade e de reciprocidade.

Na tipologia proposta em Silva (2007) as dimensões de análise são: relação ser humano-meio ambiente, ciência e tecnologia, valores éticos, política e práticas pedagógicas (atividades). Em cada uma dessas dimensões foram agrupados elementos que, em conjunto, buscam inferir a concepção de educação ambiental predominante. É importante ressaltar que a seleção dos elementos dentro de cada concepção reflete, de uma forma genérica, os casos considerados mais característicos de cada uma. Devido à própria complexidade da educação ambiental, não é tarefa fácil identificar onde termina uma dimensão e onde começa outra. Portanto, a tipologia proposta (Quadro 1) reflete uma série de escolhas e representa uma possibilidade de interpretação de concepções de educação ambiental. 
Quadro 1. Tipologia de concepções de educação ambiental e dimensões para a análise (SILVA, 2007).

\begin{tabular}{|c|c|c|c|}
\hline \multirow{2}{*}{$\begin{array}{c}\text { Dimensões } \\
\text { de análise }\end{array}$} & \multicolumn{3}{|c|}{ Caracterização da Educação Ambiental } \\
\hline & Concepção Conservadora & Concepção Pragmática & Concepção Crítica \\
\hline $\begin{array}{l}\text { Relação } \\
\text { ser humano- } \\
\text { ambiente }\end{array}$ & $\begin{array}{l}\text { - dicotomia ser humano- } \\
\text { ambiente; } \\
\text { - ser humano como } \\
\text { destruidor; } \\
\text { - retorno à natureza primitiva } \\
\text { (arcaísmo ou idilismo); } \\
\text { - catastrofismo; } \\
\text { - busca harmonia ser } \\
\text { humano- natureza; } \\
\text { - ser humano faz parte da } \\
\text { natureza em sua dimensão } \\
\text { biológica (reducionismo } \\
\text { biológico). }\end{array}$ & $\begin{array}{l}\text { antropocentrismo; } \\
\quad \text { ser humano capaz de } \\
\text { usar sem destruir; } \\
\text { - ser humano como biológico } \\
\text { e social; } \\
\text { - lei de ação e reação (natureza } \\
\text { vingativa); } \\
\text { - precisa proteger o ambiente } \\
\text { para poder sobreviver; } \\
\text { - meio ambiente - bem para } \\
\text { servir o ser humano. }\end{array}$ & $\begin{array}{l}\text { complexidade da relação; } \\
\text { - ser humano pertence à teia } \\
\text { de relações sociais, naturais e } \\
\text { culturais e vive em interação; } \\
\text { - relação historicamente } \\
\text { determinada; } \\
\text { - ser humano como } \\
\text { biopsicossocial, dotado de } \\
\text { emoções. }\end{array}$ \\
\hline $\begin{array}{l}\text { Ciência e } \\
\text { Tecnologia }\end{array}$ & $\begin{array}{l}\text { cientista/especialista } \\
\text { como único detentor do } \\
\text { saber; } \\
\text { base empirista - } \\
\text { conhecimento como algo } \\
\text { externo ao cientista; } \\
\text { - ciência como portadora da } \\
\text { verdade e da razão; } \\
\text { - produção científica isolada } \\
\text { da sociedade. }\end{array}$ & $\begin{array}{l}\text { - relação entre ciência e } \\
\text { sociedade de uma forma } \\
\text { utilitária; } \\
\text { - conhecimento científico } \\
\text { ocorre de forma linear; } \\
\text { - ênfase nos resultados; } \\
\text { - resolução dos problemas } \\
\text { ambientais pela ciência e } \\
\text { tecnologia; } \\
\text { - supremacia do saber } \\
\text { científico sobre o popular. }\end{array}$ & $\begin{array}{l}\text { - conhecimento científico como } \\
\text { produto da prática humana; } \\
\text { - interdisciplinaridade na } \\
\text { produção do conhecimento; } \\
\text { - processo de investigação } \\
\text { envolve rupturas e mudanças } \\
\text { de rumo; } \\
\text { - ciência como uma das formas } \\
\text { de interpretação do mundo; } \\
\text { - cultura local como } \\
\text { conhecimento. }\end{array}$ \\
\hline $\begin{array}{l}\text { Valores } \\
\text { éticos }\end{array}$ & $\begin{array}{l}\text { - questões que envolvem } \\
\text { conflitos não são abordadas; } \\
\text { - padrões r de } \\
\text { comportamento em uma } \\
\text { perspectiva maniqueísta; } \\
\text { - todos são igualmente } \\
\text { responsáveis } \\
\text { problemas e pela qualidade } \\
\text { ambiental. }\end{array}$ & $\begin{array}{l}\text { - conflito apresentado como } \\
\text { um "falso consenso"; } \\
\text { solução depende do } \\
\text { querer fazer; } \\
\text { ênfase nos } \\
\text { comportamentos individuais - } \\
\text { postura normativa; } \\
\text { - relação direta entre } \\
\text { informação e mudança de } \\
\text { comportamento. }\end{array}$ & $\begin{array}{l}\text { - questões controversas são } \\
\text { apresentadas na perspectiva de } \\
\text { vários sujeitos sociais; } \\
\text { - questões de igualdade de } \\
\text { acesso aos recursos naturais e } \\
\text { distribuição desigual de riscos } \\
\text { ambientais são discutidas; } \\
\text { - incentivo à formação de } \\
\text { valores e atitudes direcionados } \\
\text { pela ética e justiça ambiental. }\end{array}$ \\
\hline $\begin{array}{l}\text { Participação } \\
\text { Política }\end{array}$ & $\begin{array}{l}\text { - não há uma } \\
\text { contextualização política e } \\
\text { social dos problemas } \\
\text { ambientais; } \\
\text { - a dimensão da participação } \\
\text { política não aparece. }\end{array}$ & $\begin{array}{l}\text { participação do Estado } \\
\text { como projetos e normas; } \\
\text { oposição entre o social e } \\
\text { natural; } \\
\text { - cidadão é o consumidor; } \\
\text { - propostas de atuação } \\
\text { individual. }\end{array}$ & $\begin{array}{l}\text { proposta de "cidadania } \\
\text { ativa"; } \\
\text { responsabilidades das } \\
\text { diferentes instâncias (sociedade } \\
\text { civil, governo, ONGs); } \\
\text { fortalecimento da } \\
\text { sociedade civil; } \\
\text { - ênfase na participação } \\
\text { coletiva. }\end{array}$ \\
\hline $\begin{array}{l}\text { Práticas } \\
\text { pedagógicas }\end{array}$ & $\begin{array}{l}\text { - atividades de } \\
\text { contemplação; } \\
\text { - datas comemorativas; } \\
\text { - atividades externas de } \\
\text { "contato com a natureza" } \\
\text { com fim em si mesma. }\end{array}$ & $\begin{array}{l}\text { - atividades "técnicas/ } \\
\text { instrumentais" sem propostas } \\
\text { de reflexão (e.x.: separar } \\
\text { materiais para reciclagem); } \\
\text { - resolução de problemas } \\
\text { ambientais como atividade- } \\
\text { fim; } \\
\text { - atividades que apresentem } \\
\text { resultados rápidos. }\end{array}$ & $\begin{array}{l}\text { - propostas de atividades } \\
\text { interdisciplinares; } \\
\text { - resolução de problemas } \\
\text { como temas geradores; } \\
\text { - exploram-se potencialidades } \\
\text { ambientais locais/regionais; } \\
\text { - estudo do meio; } \\
\text { - role-play - tema controverso. }\end{array}$ \\
\hline
\end{tabular}




\section{A aplicação da tipologia de análise}

\section{a) Análise de programas educativos na televisão}

A primeira utilização da tipologia, que gerou sua construção, foi a análise de uma série de filmes de meio ambiente exibidos na TV Escola (SILVA, 2007). A partir de uma análise exploratória de 57 filmes exibidos no canal do MEC de 1998 a 2003, dentro do bloco de programação Meio Ambiente, foi escolhida a série "Meio Ambiente e Cidadania", que foi produzida pelo MEC em 1998 e transmitida até 2002. A série é constituída de 10 programas com os seguintes temas: Apresentação, Ecossistema, Energia, Água, Lixo, Saneamento, Poluição, Solo, Ambiente Social, Horta. A escolha da série se deu pelos seguintes aspectos: é composta de 10 filmes que tentam abranger uma boa parte dos temas relacionados ao meio ambiente; há um programa específico relacionado ao ambiente social; a série foi produzida pelo próprio Ministério da Educação com o objetivo específico de ser veiculada na TV Escola; o fato de ser dirigida ao professor, embora possa também ser utilizada com alunos.

Para analisá-los, realizamos a transcrição das falas e fizemos um processo de captura de imagens. Na transcrição, optamos por fazer duas colunas: uma com a transcrição do áudio e a outra com comentários sobre a locução e o enquadramento e com as imagens consideradas mais significativas para a identificação da concepção. A análise foi realizada de forma transversal, ou seja, não analisamos cada programa individualmente, mas cada uma das dimensões. Por exemplo, na análise da relação ser humano-meio ambiente foram selecionados trechos/recortes/imagens de vários programas que apresentavam concepções dessa dimensão, e assim também nas outras.

No que se refere à dimensão da relação ser humano-meio ambiente, as análises indicaram que o material converge no sentido de uma concepção ora conservadora, ora pragmática. Conservadora, uma vez que aparecem elementos que indicam a dicotomia da relação, em que o ser humano é apontado como uma presença intrusa e destruidora, gerando o impasse: de um lado o ser humano precisa retirar elementos da natureza para sua sobrevivência e de outro é chamado a mantê-la intocada. Os elementos da concepção pragmática indicam que o ser humano pode usar sem destruir e há um forte apelo ao sobrevivencialismo, ou seja, o ser humano precisa proteger o ambiente para poder sobreviver. Não é apresentada a real complexidade da relação, uma vez que a abordagem não faz referências ao fato de a relação ser historicamente determinada e que o ser humano pertence à teia de relações sociais, naturais e culturais e vive em interação.

$\mathrm{Na}$ dimensão da Ciência e Tecnologia observamos que estratégias de produção científica e tecnológica orientadas pela interdisciplinaridade não são contempladas. O que predomina são os argumentos de especialistas de determinadas áreas apresentando tecnicamente um aspecto específico da temática ambiental. A Ciência e Tecnologia são mostradas como solucionadoras dos problemas ambientais. Os filmes não fazem menção aos processos de 
investigação nem indicam que o conhecimento científico envolve rupturas e mudanças de rumo. Também observamos a supremacia do saber científico sobre o popular. De acordo com nossa tipologia de análise, as visões de Ciência e Tecnologia apresentadas nos filmes indicam uma concepção essencialmente pragmática de EA.

No tocante à dimensão dos valores éticos, observamos alguns elementos da perspectiva conservadora de EA, uma vez que a responsabilidade pelos problemas ambientais é distribuída igualmente por todas as classes sociais. No entanto, a maior parte dos discursos que se referem a essa dimensão segue a concepção pragmática de EA, pois expressam uma relação direta entre informação e mudança de comportamento. A maior parte dos filmes tem como estratégia apresentar de início alguns comportamentos considerados incorretos, depois apresentar informações relacionadas ao problema e no final chamar a atenção do espectador para prescrições de comportamentos "ambientalmente corretos" ou solicitar mudanças nos hábitos apresentados. Também foi observado um posicionamento moral de que a mudança ambiental depende apenas do "querer fazer". No que se refere às situações que envolvem conflitos, observamos que são evitadas em todos os programas.

$\mathrm{Na}$ dimensão política, encontramos elementos das três concepções descritas. Observamos que os filmes não fazem uma contextualização política e social dos problemas ambientais, sendo essa descontextualização parte de uma concepção conservadora de EA. São apresentadas algumas propostas governamentais solicitando a participação da população. No entanto, não são descritas as propostas nem as formas de participação. Nesse sentido, notamos que há um esvaziamento do papel do Estado, cuja responsabilidade é apenas ditar as normas de conduta por meio de leis. Além disso, a possibilidade de uma "cidadania ativa" é desconsiderada. Tais elementos indicam uma concepção de EA pragmática. No entanto, na análise dessa dimensão, observamos alguns elementos da concepção de EA Crítica, visto que alguns programas indicam formas de participação coletiva, principalmente por meio de associações.

No que tange às atividades propostas, observamos que são sugeridas, principalmente por meio de imagens, atividades de campo e de reconhecimento de flora e fauna locais, as quais atrelamos à perspectiva da EA conservadora. Embora a maioria dos filmes enfatize no final a importância do reconhecimento da realidade local, observa-se que a resolução de problemas ambientais locais passa a ser uma atividade-fim, e não um tema gerador de reflexão, como propõe a práxis crítica, estando mais inclinada ao pragmatismo. Em relação às atividades interdisciplinares, foram encontrados alguns exemplos no material de apoio e um exemplo nos filmes.

Aplicando nossa tipologia de análise, observamos que, embora elementos das outras concepções tenham sido identificados, a concepção de EA que prevalece no conjunto dos filmes da série "Meio Ambiente e Cidadania" é a Pragmática.

Podemos inferir, portanto, que a tipologia desenvolvida permitiu aprofundar as análises e identificar sentidos, muitas vezes ocultos, nos discursos e imagens 
dos filmes. Outras duas pesquisas posteriores que utilizaram a tipologia são descritas a seguir.

\section{b) Análise de capas de revista}

Em Silva (2008), foi realizada uma análise da imagem de nove capas de revistas de grande circulação, mais especificamente, Época, Veja, Carta Capital, Nova Escola e Scientific American Brasil. Foram selecionadas capas de revistas publicadas de outubro de 2006 a março de 2008 que traziam edições especiais sobre o tema meio ambiente. Bardin (1977, p. 35) destaca que "as imagens também podem ser analisadas como conteúdo". Dessa forma, buscou-se um tratamento analítico categorial, agrupando-se as capas que traziam interpretações semelhantes, com base na identificação dos itens descritos na tipologia.

Duas revistas traziam imagens na capa de "catástrofe ambiental", expressas pela cor preta, em uma delas, e pela figura do despertador, representando que "temos pouco tempo" ou "vamos preservar enquanto há tempo", em uma perspectiva catastrófica. Ainda em uma concepção conservadora, ressalta-se a imagem da família de ursos polares com expressões que revelam a fragilidade, destacando-se no texto “as primeiras vítimas". Nessas capas são priorizados aspectos naturais em perspectiva fatalista.

Duas capas são bem semelhantes: apresentam fotos de pessoas aparentando serem de classe social média/alta e instruídas, o que é possível inferir pelas roupas (verdes e "modernas") e "posturas ecológicas" propagadas como "comportamentos ambientalmente corretos" como filho único. São destacadas por textos sobre comportamentos, como andar de bicicleta, consumir apenas alimentos orgânicos e usar calçados de sola de pneu, além da indicação para a cabeça apontada como "consciência ecológica". Nessas capas, são propostas soluções que só são válidas para determinadas conjunturas de segmento social. De um modo geral, as revistas buscam apontar padrões de comportamentos a serem seguidos por aqueles que desejam "salvar o planeta", mostrando um posicionamento moral, como se a solução dependesse apenas do querer fazer, e reduzindo a complexidade da questão. Foi observado também um chamamento à participação individual: "O que você pode fazer...". Essas propostas de "caminhos para a salvação do planeta" e de poder individual ("você pode salvar") aparecem associadas exclusivamente à ética e à consciência individual, como se essas estivessem separadas da dimensão social e política.

Em outra capa o indivíduo é tratado como consumidor que deve continuar comprando sempre mais, só que agora, os "produtos sustentáveis", oferecidos por lojas, fábricas e supermercados que "neutralizam suas emissões de $\mathrm{CO}_{2}$ ", que vem em uma "embalagem reciclada" e fazendo empréstimos em "bancos ecológicos". Sobre esse aspecto do consumo, ressalta-se que a publicidade interna da maioria dessas revistas é voltada aos produtos e empresas sustentáveis (são edições ditas ecológicas). Embora entendamos que a sustentabilidade seja um importante aspecto a ser pensado pelas empresas da atualidade, o incentivo a um consumo cada vez maior e descomprometido com a realidade social parece- 
nos apontar para o paradoxo da problemática ambiental: incentiva-se o consumo, só que agora, de "produtos verdes".

Uma das revistas mostra uma mão (da professora) apoiando a outra (do aluno), que segura uma planta, bem como a frase "Ajudar os alunos a garantir o futuro do planeta", também em uma ênfase a aspectos de salvação e aos resultados.

Essas quatro capas, após análise de elementos da tipologia, principalmente aqueles da dimensão dos valores e participação política, mostraram evidências de uma concepção pragmática.

As revistas que apresentaram imagens de capa com alguns elementos da concepção crítica foram aquelas dirigidas ao público constituído em sua maioria por professores e/ou acadêmicos. Uma delas, ao apresentar um menino indiano no rio (país onde os rios são considerados sagrados), pode suscitar interpretação da questão cultural do rio na Índia, representado pelo semblante de tranquilidade do menino. No entanto, a capa também parece se propor a gerar um sentimento de pena da situação da criança, pela sujeira do rio e por não entendermos essa forma de cultura. A capa da outra revista, de divulgação, representa alguns problemas e soluções ambientais, entendidos como responsabilidade de diversos segmentos da sociedade. Esse apelo à participação coletiva constitui um dos elementos da concepção crítica da questão ambiental.

A análise das imagens das capas revela que, na maior parte, os valores são apresentados como se fossem atemporais e universais. A tipologia construída, embora enfoque as concepções de educação ambiental, que não necessariamente eram os objetivos das revistas, contribuiu para identificarmos elementos que prevaleceram no conjunto dessas imagens midiáticas, principalmente aqueles referentes às dimensões da relação ser humano-meio ambiente, dos valores éticos e da participação política.

\section{c) Análise de um projeto de intervenção}

O "Projeto Coração[-]Roxo de Biomonitoramento e Educação Ambiental" foi uma experiência que uniu alunos de ensino médio de uma escola pública no município de Cubatão, estado de São Paulo, e pesquisadores do Laboratório de Poluição Atmosférica Experimental (LPAE), vinculado ao Departamento de Patologia da Faculdade de Medicina da Universidade de São Paulo (FMUSP), e está descrito em todas as suas etapas em uma tese de doutorado (CAMPINA, 2008) que utilizou como um dos seus elementos de análise a tipologia proposta.

As atividades de biomonitoramento, realizadas pelos estudantes da escola sob orientação da pesquisadora, que também era professora de ensino médio, utilizavam a espécie Tradescandia pallida (TRAD - mcn), popularmente conhecida como coração-roxo. A estratégia se baseou em uma experiência semelhante do programa Eurobionet (rede europeia para a avaliação de qualidade do ar usandose plantas bioindicadoras) realizada com estudantes. O programa mostrou que as plantas bioindicadoras monitoram de forma muito eficiente a qualidade do ar e, portanto, são recomendadas para atividades de educação ambiental. Verificou-se 
a possibilidade de incentivo à iniciação da pesquisa científica e maior respeito ao meio ambiente (KLUMP et al., 2001).

A aproximação iniciou-se em 2001, mas o grupo, foco da pesquisa relatada a seguir, realizou seus estudos entre 2005 e 2007. Cerca de 40 alunos do $1^{\circ}$ ano do Ensino Médio iniciaram o trabalho e cerca de 20 participaram das etapas de pesquisa do início ao fim, desde a fase de elaboração até a execução e divulgação. Nessa ação educativa levou-se para dentro de uma escola pública um método de investigação ambiental, já desenvolvido pelos pesquisadores da universidade, para ser posto em prática pelos alunos dessa escola, que investigaram a atmosfera local e produziram um conhecimento da atual situação ambiental da cidade. Além do biomonitoramento, muitas outras atividades foram sendo incorporadas ao processo na tentativa de se praticar uma educação ambiental referenciada na teoria crítica.

Após seu desenvolvimento, procurou-se identificar as tendências de educação ambiental evidenciadas na trajetória dessa intervenção educativa. Descreveremos aqui as principais etapas desenvolvidas, nas quais foram obtidos os dados da pesquisa:

- Reuniões - no início, o grupo se reunia uma vez por semana para discutir as ações. Com o tempo, as reuniões passaram a ser quinzenais. Nas reuniões, que eram gravadas, realizava-se o planejamento das ações, discutia-se o cronograma do biomonitoramento e as atividades do grupo.

- Curso de biomonitoramento - foi realizado em quatro etapas distintas com a finalidade de instrumentalizar os alunos para utilizarem as técnicas do bioensaio escolhido e realizarem as leituras e contagem das células.

- Biomonitoramento - para sua realização foi elaborado o mapeamento da cidade, observando-se a proximidade ou distância do polo industrial, presença ou não de vias rodoviárias e trânsito local intenso. Foram escolhidos sete bairros para a instalação das estações de biomionitoramento. O cultivo das plantas ocorreu em 140 vasos do tipo jardineira. Cada estação contou com a exposição de vinte vasos de plantas. Foi realizada a distribuição das plantas e três coletas das inflorescências, uma a cada mês. Após o término das coletas, realizaram-se as leituras das células e a contagem dos micronúcleos. As análises estatísticas dos resultados foram realizadas pelos pesquisadores do LPAE e, posteriormente, discutidas com os alunos.

- Construção do site e palestras - foi realizada uma oficina de mídia digital por uma jornalista com o objetivo de informar os alunos sobre a construção do site e propor a contribuição dos mesmos. Também foram apresentadas palestras sobre temas relevantes ao projeto;

- Grupo focal - constituição e observação de um grupo focal realizado com os alunos, que teve por finalidade proporcionar um momento de troca de conceitos, atitudes, condições de discussão sobre o tema e maior integração entre os participantes. Todas essas reuniões foram gravadas em 
áudio e vídeo e posteriormente transcritas. Segundo Gatti (2005, p. 12), o grupo focal:

[...] é uma técnica de levantamento de dados muito rica para capturar formas de linguagem, expressões e tipos de comentários de determinado segmento [...] lembrando que não está realizando uma entrevista com um grupo, mas criando condições para que este se situe, explicite pontos de vista, analise, infira, faça críticas, abra perspectivas diante da problemática.

Foi utilizada a técnica da observação participante, pois, de acordo com André (1995), o "pesquisador tem sempre um grau de interação com a situação estudada, afetando-a e sendo por ela afetado". As observações foram realizadas nas reuniões em que as ações do grupo eram discutidas, nas palestras e nas atividades desenvolvidas pelos alunos. Além da observação participante, utilizamos também as gravações em vídeo de todas as atividades do Projeto Coração[-]Roxo.

$\mathrm{Na}$ busca de responder à questão: “Quais concepções de educação ambiental fundamentaram as ações desenvolvidas no Projeto Coração[-]Roxo?”, decidiu-se utilizar a tipologia em questão, que, apesar de ter sido construída para a identificação das concepções de educação ambiental em materiais didáticos, possibilitava contemplar a análise de uma ação educativa. A opção de realizar a análise à luz dessas categorias baseou-se no entendimento de que essa tipologia espelha, de modo sintético, diferentes concepções de EA, necessárias para o entendimento do processo realizado.

No âmbito das ações desenvolvidas pelo Projeto Coração[-]Roxo puderam ser identificadas as três concepções de EA destacadas na tipologia.

As atividades do projeto envolvendo os alunos iniciam-se com reuniões semanais para o planejamento das ações. Nessas reuniões, constatou-se uma oscilação entre as concepções pragmática e conservadora. Em relação à primeira, observou-se que a transmissão do conhecimento científico ocorreu de forma linear, uma vez que não houve participação dos alunos na formulação da proposta metodológica do biomonitoramento. Além disso, entendeu-se que, nesse momento, a relação entre ciência e sociedade foi estabelecida de forma utilitária e o cientista aparecia como único detentor do saber, visto que não houve a inclusão dos saberes trazidos pelos alunos.

$\mathrm{O}$ curso de biomonitoramento realizado com os alunos pode ser considerado essencialmente pragmático, de acordo com o referencial de análise. Para que a técnica do biomonitoramento fosse aprendida pelos alunos, foram necessárias várias aulas teóricas e práticas para a utilização do microscópio, confecção das lâminas e leitura destas. Sendo assim, destacou-se o comportamento normativo, a supremacia do saber científico sobre o popular e a utilização de atividades técnico-instrumentais.

A concepção crítica fica explicitada quando se avalia a reflexão dos alunos, a iniciativa de organizarem-se em grupos de estudos a fim de buscarem alternativas 
para aprimorarem seu próprio conhecimento sobre a situação ambiental de Cubatão, identificando que o processo de investigação envolve rupturas e mudanças de rumo e que a ciência é uma das formas de interpretação do mundo.

O estabelecimento, pelo grupo, de critérios de escolha tanto dos locais de exposição das plantas como de cultivo pode ser relacionado à EA crítica, porquanto o conhecimento científico é tratado como produto da prática humana.

A proposta dos alunos de que fossem incluídas atividades complementares ao conhecimento já adquirido possibilitou o aprimoramento de uma EA crítica, visto que a interdisciplinaridade na produção do conhecimento, a apresentação das questões controversas na perspectiva de vários sujeitos sociais e a realização de estudos do meio são identificadas com essa concepção.

Nessa conceituação teórica, destacam-se vários elementos para a classificação das ações em que os alunos do projeto interagiram com seus pares: apresentação do projeto à comunidade escolar, oficinas com alunos de outras escolas, trazendo elementos que mostram a ciência como uma das formas de interpretação do mundo, incentivo à formação de valores e atitudes direcionados pela ética e justiça ambiental e proposta de cidadania ativa.

Nas ações em que houve interação dos alunos com a comunidade (evento de EA para a comunidade, participação em feiras), destacam-se os tópicos: responsabilidades das diferentes instâncias, fortalecimento da sociedade civil, ênfase na participação coletiva, questões de igualdade de acesso aos recursos naturais e distribuição desigual de riscos ambientais.

No processo de construção do site do projeto, durante a apresentação da proposta, que ainda estava sendo elaborada, houve também participação ativa dos alunos, a qual ficou evidente nas sugestões dadas para a escolha dos sujeitos das entrevistas publicadas no site e nos conteúdos abordados, assim como na forma de realização da atividade.

Os conceitos adquiridos no curso de biomonitoramento foram aplicados nesse momento do projeto, nas atividades de exposição das plantas, nas coletas, nas leituras das lâminas e nos registros. Tanto no curso quanto nas ações, a perspectiva presente foi pragmática, com ênfase ao comportamento normativo e ao conhecimento científico, entendido como linear.

Todavia, na apresentação e discussão dos resultados do biomonitoramento com os alunos, ficaram evidentes aspectos da perspectiva crítica, uma vez que eles demonstraram aptidão ao realizarem associação entre o conhecimento adquirido ao longo do desenvolvimento do projeto e a formação de novos conceitos, colocando em prática a interdisciplinaridade na produção do conhecimento.

A utilização da técnica de grupo focal promoveu maior interação dos alunos, já que se trata de uma técnica participativa, e as discussões que apareciam indicavam que esse momento formativo estava contribuindo para a construção da cidadania ativa dos participantes.

Após a análise das ações, constata-se que o Projeto Coração[-]Roxo identifica-se com a perspectiva conservadora e a pragmática em certos 
momentos, como, por exemplo, na primeira reunião de planejamento e estudos, no curso do biomonitoramento e na aprendizagem do cultivo das plantas. Entende-se que as perspectivas citadas embasaram essas fases por terem sido empregados procedimentos aprendidos e reproduzidos pelos alunos.

Contudo, no restante das ações, ficam evidenciados elementos da perspectiva crítica. Tais momentos indicaram um processo de aprendizagem dinâmico e reflexivo, que consistiu na apropriação do conhecimento ambiental local para se intervir na comunidade. Desse modo, a tipologia também permitiu a análise das práticas do projeto e a identificação de sentidos da educação ambiental que perpassaram suas etapas.

\section{Considerações finais}

Contribuíram para as reflexões deste artigo os resultados obtidos no Grupo de Discussão e Pesquisa (GDP) Educação Ambiental no Contexto Escolar, durante o III Encontro de Pesquisa em Educação Ambiental. Esses resultados foram publicados em Guerra e Guimarães (2007). Nas considerações desse GDP destacou-se que era preciso ficar clara a questão da complexidade da discussão sobre "o que é EA e de que modo a mesma envolve diferentes formações, conhecimentos, representações sociais e visões de mundo". Também se ressaltou o entendimento de que é necessária a análise e reflexão das práticas educativas pelos próprios professores e de que é preciso "criar mecanismos para pesquisas acessíveis à realidade da escola" (GUERRA; GUIMARÃES, 2007).

Entendemos que a tipologia de concepções de EA, com suas dimensões para análise, apresenta uma contribuição metodológica aos professores, uma vez que foi construída e embasada por diversos referenciais teóricos, demonstrando ser possível sua utilização para estudos de outras situações que envolvam a compreensão de sentidos da EA. Nas situações de análise apresentadas neste artigo a tipologia foi utilizada de forma diferente, prevalecendo um aprofundamento das dimensões, no caso dos vídeos, e das categorias de concepções em seu conjunto, no caso das revistas e da intervenção.

Ressaltamos que, considerando a própria complexidade da área, assim como outras categorizações, a tipologia apresentada não pretende ser absoluta, abarcando todos os aspectos da educação ambiental. Por meio de suas dimensões, tal tipologia permitiu identificar características principais expressas nos materiais e ações analisados. Também pode possibilitar um olhar mais crítico para as diferentes manifestações da questão ambiental que estão presentes na mídia, o que resultaria em uma melhor contextualização desses elementos em práticas de sala de aula. No entanto, a triangulação de dados com outros métodos de pesquisa sempre se fará necessária.

No momento em que temos o desafio de contribuir para uma educação ambiental que resgate o papel da escola na mudança social, nosso trabalho pretende oferecer subsídios para o reconhecimento de dimensões e a proposição de ações que caminhem ao encontro de uma proposta de educação crítica e transformadora. 


\section{Referências}

ANDRÉ, M. E. D. A Etnografia da prática escolar. Campinas, SP: Papirus, 1995.

BARDIN, L. Análise de conteúdo. Lisboa: Edições 70, 1977.

CAMPINA, N. N. Projeto Coração Roxo de Biomonitoramento e Educação Ambiental:

análise de uma experiência com alunos de uma escola pública no município de Cubatão

- SP. 2008. 128 f. Tese (Doutorado em Ciências) - Faculdade de Medicina, Universidade de São Paulo, São Paulo, 2008.

CARVALHO, I. C. de M. As transformações da cultura e o debate ecológico: desafios políticos para a educação ambiental. In: NOAL, F. O.; REIGOTA, M.; BARCELOS, V. H. L. Tendências da Educação Ambiental Brasileira. Santa Cruz do Sul: EDUNISC, 1998. p. 113-126.

O "Ambiental" como valor substantivo: uma reflexão sobre a identidade da educação ambiental. In: SAUVÉ, L.; ORELLANA, I.; SATO, M. Textos escolbidos em educação ambiental: de uma América à outra. Montreal: Publications ERE-UQAM, 2002. p. 85-90. (Tomo I). (Versão em português).

. Educação Ambiental: a formação do sujeito ecológico. São Paulo: Cortez, 2004.

CARVALHO, I. C. de M.; SCHMIDT, L. S. A pesquisa em educação ambiental: uma análise dos trabalhos apresentados na ANPEd, ANPPAS e EPEA de 2001 a 2006. Pesquisa em Educação Ambiental, v. 3, n. 2, p. 147-174, jul./dez. 2008.

CARVALHO, L. M. de. A educação ambiental e a formação de educadores. In: SECRETARIA DE ENSINO FUNDAMENTAL. Panorama da Educaşão Ambiental no Ensino Fundamental. Brasília: MEC, SEF, 2001. p. 55-63.

A temática ambiental e o processo educativo: dimensões e abordagens. In: CINQUETTI, H. S.; LOGAREZZI, A. Consumo e resíduos: fundamentos para o trabalho educativo. São Carlos: EdUFSCar, 2006. p. 19-41.

CRESPO, S. Educar para a sustentabilidade: a educação ambiental no programa da Agenda 21. In: NOAL, F. O.; REIGOTA, M.; BARCELOS, V. H. L. Tendências da Educação Ambiental Brasileira. Santa Cruz do Sul: EDUNISC, 1998. p. 211-225.

GATTI, B. A. Grupo Focal na Pesquisa em Ciências Sociais e Humanas. Brasília: Líber Livro, 2005.

GUERRA, A. F. S.; GUIMARÃES, M. Educação Ambiental no contexto escolar: questões levantadas no GDP. Pesquisa em Educação Ambiental, v. 2, n. 1, p. 155-166, jan./jun., 2007.

KLUMPP, A; ANSEL, W, KLUMPP, G, FOMIN, A. Um novo conceito de monitoramento e comunicação ambiental: a rede européia para a avaliação da qualidade do ar usando plantas bioindicadoras (Eurobionet). Revista Brasil. Bot., São Paulo, v. 24, n. 4 (suplemento), p. 511-518, dez. 2001.

KRASILCHIK, M. Educação ambiental na escola brasileira - passado, presente e futuro. Cienc. Cult., Rio de Janeiro, v. 38, n. 12, p. 1958-1961, dez. 1986.

. Educação Ambiental. Ciência \& Ambiente, Santa Maria, RS, n. 8, p. 71-79, jan./jun. 1994. 
LAYRARGUES, P. P. (Coord.). Identidades da Educação Ambiental Brasileira. Brasília: Ministério do Meio Ambiente, 2004.

LOUREIRO, C. F. B. Trajetória e fundamentos da Educação Ambiental. São Paulo: Cortez, 2004.

. Educação ambiental e "teorias críticas”. In: GUIMARÃES, M. (Org.). Caminhos da educação ambiental: da forma à ação.Campinas, SP: Papirus, 2006. p. 51-86.

MA, T. H. Tradescantia micronucleus bioassay and pollen tube chromatic aberration test for in situ monitoring and mutagens screening. Environ. Health Perspect, v. 37, p. 85-90, 1981.

MELLO, C. M. Trilhando diferentes caminhos na educação ambiental: as concepções de educação ambiental do programa do Núcleo Santa Virgínia e agentes sociais envolvidos. 2000. 119 f. Dissertação (Mestrado em Educação) - Faculdade de Educação, Universidade de São Paulo, São Paulo, 2000.

PELICIONI, A. F. Desvelando representações e práticas sociais em educação ambiental. In: RIBEIRO, H. (Org.) Olhares geográficos: meio ambiente e saúde. São Paulo: SENAC, 2005. p. 163-180.

REIGOTA, M. Meio ambiente e representação social. São Paulo: Cortez, 1995. (Coleção Questões de Nossa Época).

SAUVÉ, L. Environmental Educations: possibilities and contraints. Connect, v. XXVII, n. $1 / 2$, p. 1-4, 2002.

. Uma cartografia das correntes em educação ambiental. In: SATO, M.; CARVALHO e col. Educação Ambiental: pesquisa e desafios. Porto Alegre: Artmed, 2005. p. 17-44.

SILVA, R. L. F. da. O meio ambiente por trás da tela - estudo das concepções de educação ambiental dos filmes da TV Escola. 2007. 267 f. Tese (Doutorado em Educação) Faculdade de Educação, Universidade de São Paulo, São Paulo, 2007.

. Imagens e Interpretação em Educação Ambiental. In: REUNIÃO ANUAL DA ANPED - GT 22, 31., 2008, Caxambu, MG. Anais... Caxambu: 2008.

SORRENTINO, M. De Tbilisi a Thessaloniki, a educação ambiental no Brasil. In: CASCINO, F.; JACOBI, P.; OLIVEIRA, J. F. (Org.). Educação, Meio Ambiente e Cidadania: reflexões e experiências. Secretaria de Estado do Meio Ambiente/Coordenadoria de Educação Ambiental. São Paulo: 1998. p. 27-32.

TOZONI-REIS, M. F. de C. Contribuições para uma pedagogia crítica da Educação Ambiental: reflexões teóricas. In: LOUREIRO, C. F. B. (Org.). A questão ambiental no pensamento crítico: natureza, trabalho e educação. Rio de Janeiro: QUARTET, 2007. p. 177219.

. Pesquisa-ação em educação ambiental. Pesquisa em Educação Ambiental, v. 3, n. 1, p. $155-169,2008$. 